\title{
O conceito de currículo oculto e a formação docente
}

\author{
Viviane Patricia Colloca Araujo ${ }^{1}$
}

\section{Resumo}

Este artigo, em linhas gerais, apresenta uma análise sobre o conceito de Currículo Oculto e a relevância de estudá-lo na formação de professores. O currículo é entendido aqui como um conjunto de experiências educativas vividas pelos estudantes dentro do contexto escolar, como um todo organizado em função de propósitos educativos e de saberes, atitudes, crenças e valores que expressam e concretizam formal e informalmente o ensino. O estudo sobre o conceito de Currículo Oculto foi bastante intenso nas décadas de 1960 a 1980, quando os teóricos das teorias críticas do currículo demonstraram que se ensinava na escola muito mais do que conscientemente se revelava. Com efeito, este artigo busca a partir de estudos bibliográficos destacar que o currículo oculto está vivo dentro do ambiente escolar, o que demonstra a necessária discussão sobre o tema, pois esses ensinamentos influenciam sobremaneira na formação da identidade dos alunos.

Palavras-Chave: Currículo Oculto. Formação de Identidade. Aprendizagens Implícitas.

\begin{abstract}
This article, in general terms, presents an analysis on the concept of Occult Curriculum and the relevance of studying it in teacher training. The curriculum is understood here as a set of educational experiences lived by students within the school context, as a whole organized according to educational purposes and knowledge, attitudes, beliefs and values that express and formally materialize and informally teach. The study of the concept of the Hidden Curriculum was quite intense in the 1960s to 1980s, when critical theorists of the curriculum demonstrated that it was taught at school much more than it consciously revealed itself. In fact, this article searches from bibliographic studies to highlight that the hidden curriculum is alive within the school environment, which demonstrates the necessary discussion about the subject, since these teachings greatly influence the formation of students' identity.
\end{abstract}

Keywords: Hidden Curriculum. Identity Formation. Implicit Learning.

\footnotetext{
1 Doutora em Educação (PPGE/UFSCar); Mestra em Educação (PPEG/UFSCar); Licenciada em Pedagogia (UFSCar). Professora Titular da Universidade Paulista - UNIP. Coordenadora local e professora do curso de Pedagogia da UNIP/Ribeirão Preto. E-mail: vpcolloca@hotmail.com
} 
Introdução

Estudar o tema currículo não é algo simples. A palavra currículo é muito abrangente e possui diversos significados, dependendo do lugar e da finalidade para qual está sendo utilizada. Quando utilizamos o termo currículo na escola, apesar de delimitar o espaço, ainda assim encontramos diferentes possibilidades de interpretação.

Assim, o currículo é muito mais do que uma listagem de conteúdos a serem ensinados nas escolas, mas como um conjunto de experiências educativas vividas pelos estudantes dentro do contexto escolar, como um todo organizado em função de propósitos educativos e de saberes, atitudes, crenças, valores que expressam e concretizam formal e informalmente o ensino, ou seja, tanto por meio do currículo prescrito como do currículo oculto. Mas, o que isso quer dizer?

O currículo prescrito está predefinido tanto em nível nacional nos documentos oficiais como leis, normas e diretrizes nacionais, livros didáticos, propostas curriculares, como em nível local nas escolas como os planos de ensino e planos de aula feitos pelos professores. Portanto, esse currículo está registrado e documentado. No entanto, na escola não se ensina somente o que está formalmente definido. Há ensinamentos e aprendizagens que acontecem de forma implícita, ou seja, nas entrelinhas das relações que se estabelecem no ambiente escolar. Silva (2003) categoriza essas aprendizagens informais como currículo oculto. Segundo ele, “[...] o currículo oculto é constituído por todos aqueles aspectos do ambiente escolar que, sem fazer parte do currículo oficial, explícito, contribuem, de forma implícita, para aprendizagens sociais relevantes" (p. 78). Desse modo, no currículo oculto são aprendidos comportamentos, atitudes, valores e orientações que a sociedade requer das novas gerações para que se ajustem às estruturas e ao funcionamento da sociedade já constituída.

Essas considerações demonstram o quanto é relevante estudar, compreender e analisar o currículo, pois pensar sobre o currículo escolar implica em buscar compreender: o que se ensina na escola? Por que se ensina esse conhecimento? Que tipo de pessoa se está formando? Para qual tipo de sociedade essa formação é importante? Enfim, pensar o currículo envolve pensar o que se faz na escola, tanto explícita como implicitamente.

$\mathrm{O}$ currículo, de modo geral, é uma área bastante discutida na literatura educacional, vários autores já se debruçaram e continuam se debruçando sobre o tema, demonstrando a sua relevância na educação e na melhoria da qualidade do ensino. A partir da década de 1990, no Brasil, o currículo passou a estar na ordem do dia, ou seja, tornou-se alvo privilegiado da atenção de autoridades, políticos, professores e especialistas. Segundo Moreira (1997, p. 7), "sua centralidade no panorama educacional brasileiro contemporâneo pode ser atestada pelas constantes reformas dos currículos dos diversos graus de ensino, bem como pelo incremento da produção teórica do campo", e hoje, após a homologação da Base Nacional Comum Curricular (BNCC) referente à Educação Infantil e ao Ensino Fundamental, em dezembro de 2017, essa centralidade continua muito presente.

Em relação ao currículo oculto, seu estudo foi bastante intenso nas décadas de 1960 a 1980, quando os teóricos das teorias críticas do currículo demonstraram que se ensinava na escola muito mais do que conscientemente se revelava. No entanto, o conceito foi paulatinamente enfraquecendo, como afirma Silva (2003, p. 81) “[...] numa era neoliberal de afirmação explícita da subjetividade e dos valores do capitalismo, não existe mais muita coisa oculta no currículo. Com a ascensão neoliberal, o currículo tornou-se assumidamente capitalista". Mas será que tudo está revelado? Será que esse conceito ainda não é importante para se pensar o que se ensina na escola? Qual a relevância de se estudar esse conceito nos cursos de formação de professores? São essas questões que movem 
as reflexões aqui apresentadas que buscam nas teorias pós-críticas do currículo ferramentas que demostram que ainda há potencial de análise desse conceito para o momento atual da educação, pois essas teorias mostram que o currículo é uma prática discursiva, é vivo, é dinâmico e se realiza em todos os momentos da vivência escolar. Sendo assim, se aprende na escola muito mais do que aquilo que está registrado nos documentos oficiais. É durante a vivência escolar que as pessoas vão constituindo a sua identidade, vão aprendendo sobre quem são, quais são suas origens culturais, étnicas, raciais e vão descobrindo os diferentes valores que a nossa sociedade atribui a essa diversidade cultural. Muitas dessas questões são aprendidas por meio dos conteúdos ensinados de forma explícita, outras ficam nas entrelinhas, implícitos.

Para iniciar essa discussão, apresenta-se a seguir a origem do conceito Currículo Oculto e como esse conceito foi utilizado e interpretado nas Teorias Críticas sobre o currículo.

\section{Trajetória do conceito de Currículo Oculto}

A noção de currículo oculto exerceu uma forte e estranha atração em quase todas as perspectivas críticas iniciais sobre o currículo, mas esse conceito não surgiu nas teorias críticas, mas na sociologia funcionalista, aparecendo pela primeira vez em 1968 no livro Life in classrooms, de Philip Jackson (apud SILVA, 2003, p. 77-78), que diz que "[...] nos grandes grupos, a utilização do elogio e do poder que se combinam para dar um sabor distinto à vida na sala de aula coletivamente formam um currículo oculto, que cada estudante (e cada professor) deve dominar se quiser se dar bem na escola".

Essa noção foi aprofundada por outros autores, como Robert Dreeben, que buscaram mostrar que "[...] eram as características estruturais da sala de aula e da situação de ensino, que 'ensinavam' certas coisas: as relações de autoridade, a organização espacial, a distribuição do tempo, os padrões de recompensa e castigo" (SILVA, 2003, p. 78).

Esses autores da sociologia funcionalista buscaram mostrar por meio do currículo oculto, que os comportamentos desenvolvidos na escola são necessários para o funcionamento das sociedades "avançadas", ou seja, esses comportamentos ensinados por meio do currículo oculto eram importantes para o bom funcionamento da sociedade, portanto, desejáveis. Ao contrário dessa compreensão, da desejabilidade do currículo oculto, os teóricos das teorias críticas do currículo veem as atitudes e comportamentos transmitidos por meio do currículo oculto "[...] como indesejáveis dos genuínos objetivos da educação, na medida em que moldam as crianças e jovens para se adaptar às injustas estruturas da sociedade capitalista" (SILVA, 2003, p. 78).

Mas, faz-se importante entender melhor como os autores das teorias críticas analisaram, então, essas aprendizagens no currículo oculto. Seguindo uma linha cronológica, é relevante apresentar a fonte primeira das teorias críticas do currículo, ou seja, a obra de Louis Althusser, "Ideologia e Aparelhos Ideológicos de Estado", escrita em 1969, em que o autor marxista apresenta suas teses sobre como a ideologia funciona, se manifesta e conduz a vida das pessoas na sociedade capitalista. A sua grande contribuição à obra marxista está no seu raciocínio de perceber que a superestrutura, que apoia e sustenta a infraestrutura de uma sociedade, utiliza-se além da repressão e da força, da ideologia para sua perpetuação. Seu principal argumento é que o Estado, como um aparelho de sustentação da sociedade, utiliza-se de dois Aparelhos de Estado para se manter no poder, do Aparelho Repressivo e dos Aparelhos Ideológicos. 
Segundo Althusser (1987), a sociedade capitalista precisa reproduzir as condições da produção para que consiga sobreviver, ou seja, precisa reforçar as formações sociais, o lugar de cada classe social dentro do sistema econômico. Essa reprodução, por sua vez, se dará por meio da ideologia que nos é passada durante toda nossa vida em diferentes esferas, ou melhor dizendo, diferentes Aparelhos Ideológicos de Estado (família, escola, igreja, meios de comunicação, sindicatos, partidos políticos, cultura etc.), que reforçam uma determinada ideologia que nos faz acreditar que essa formação social é a mais adequada.

Seguindo a lógica do autor, a reprodução dos meios de produção se dá pela substituição do que foi gasto ou usado na produção, como matéria-prima, instalações fixas, instrumentos de produção (máquinas) etc. Já a reprodução da força de trabalho competente, apta a ser posta a funcionar no sistema complexo do processo de produção, é assegurada no regime capitalista através do sistema escolar capitalista e outras instâncias e instituições. Essa ideia nos apresenta o importante papel que o sistema escolar representa na sociedade capitalista e na sua perpetuação.

Althusser (1987) nos lança uma pergunta interessante: “Ora, o que se aprende na Escola?” (p. 20). Segundo ele, na escola se aprende muitas coisas, mas de qualquer maneira, aprende-se a ler, a escrever, a contar, portanto, se aprende algumas técnicas essenciais para a vida em cidadania. Mas se aprende muito mais coisas, inclusive elementos que podem ser rudimentares (ou pelo contrário aprofundados) de "cultura científica" ou "literária" diretamente utilizáveis nos diferentes lugares da produção, ou seja, uma instrução para os operários, outra para os técnicos, uma terceira para os engenheiros, uma outra para os quadros superiores etc. Aprendem-se, portanto, "saberes práticos".

Essa afirmação do autor demonstra que o sistema escolar é diferenciado, havendo uma formação escolar diferenciada para os vários segmentos do processo produtivo. Essa constatação de um sistema escolar dualista foi melhor desenvolvida, posteriormente, por Boudelot e Establet, na obra “L'école capitaliste en France”, em 1971.

Althusser (1987) continua seu raciocínio sobre o que se aprende na escola dizendo que lá, na escola, além dos conhecimentos e técnicas, também se aprende as regras dos bons costumes e do comportamento de cada um no sistema produtivo ${ }^{2}$. Portanto, alguns devem aprender as regras da moral, da consciência cívica e profissional, o que significa o respeito às regras da divisão social do trabalho, da dominação de classe; outros devem aprender a como comandar e, por isso, precisam falar bem, escrever bem, mandar bem, convencer bem.

Dessa forma, como bem salienta o autor, a reprodução da força de trabalho, além da qualificação do trabalhador, necessita da reprodução da submissão deste às normas estabelecidas, à ideologia da classe dominante, para que cada classe social aprenda, desde cedo, qual o seu papel e lugar na estrutura produtiva e social.

A escola, entendida portanto como reprodutora do capital cultural da classe dominante foi analisada por Bourdieu e Passeron (1975), que perceberam que o ensino encarnado na ação pedagógica tende a assegurar o monopólio da violência simbólica legítima, já que toda a ação pedagógica deverá ser considerada como violência simbólica, na medida em que impõe e inculca arbítrios culturais de um modo, também ele, arbitrário. Essa inculcação da cultura da classe dominante ocorre, segundo os autores, por meio do habitus que tende a reproduzir a integração intelectual e moral. Assim, a função do ensino é a de legitimar a cultura dominante com a finalidade de conservação social e de perpetuação das relações de classe. A escola contribui para convencer o indivíduo a permanecer no seu lugar, o seu lugar "natural".

\footnotetext{
${ }_{2} \mathrm{O}$ autor não nomeia essas aprendizagens como Currículo Oculto, mas são essas aprendizagens que são definidas como fazendo parte desse conceito.
} 
Indo além, a descrição da vida cotidiana nas salas de aula vai ser claramente politizada por autores posteriores, entre os quais S. Bowles e H. Gintis (1976). Esses autores captam a crucial importância política do currículo oculto, especialmente da forma do currículo como recurso para a reprodução, coesão e estabilidade das relações sociais de produção e distribuição.

De acordo com eles, citados por Santomé (1995), o currículo oculto se planifica, se desenvolve e se avalia sem chegar a surgir explicitamente na mente e nas intenções dos professores e, obviamente, sem ter o consentimento dos alunos e famílias. Funciona de maneira implícita por meio dos conteúdos culturais, dos hábitos, das interações e tarefas escolares. Não é fruto de uma planificação 'conspirativa' do corpo docente. Porém, o que é importante assinalar é que apresenta como resultado uma reprodução das principais dimensões e peculiaridades da esfera econômica da sociedade.

No fundo, não estamos muito longe de uma representação da instituição escolar como uma fábrica, onde o corpo estudantil se vê incitado a pensar da mesma forma, a produzir os mesmos resultados e em idêntico espaço temporal, a aceitar as mesmas recompensas e sanções, a ser julgado por autoridades externas e com parâmetros que muitas vezes não compreende [...] é assegurando logo desde a infância a reprodução de determinada consciência que as empresas preparam a próxima geração de trabalhadores e trabalhadoras. [...] É através da interação social registrada diariamente nas salas de aula que se vão construindo os significados dos objetos e das situações, que vão formando as subjetividades e se vão criando as habilidades, conhecimentos e destrezas que cada sociedade privilegia e valoriza (SANTOMÉ, 1995, p. 83).

Assim, o currículo oculto pode ser definido dentro da análise crítica do currículo como "[...] todos os aspectos do ambiente escolar que, sem fazer parte do currículo oficial, explícito, contribuem, de forma implícita, para aprendizagens sociais relevantes" (SILVA, 2003, p. 78). Isso significa que no currículo oculto se aprende fundamentalmente atitudes, comportamentos, valores e orientações que permitem que crianças e jovens se ajustem da forma mais conveniente às estruturas injustas e antidemocráticas da sociedade capitalista ao aprenderem o conformismo, a obediência e o individualismo.

Essas aprendizagens são distintas conforme a classe social das crianças e adolescentes. Assim, os filhos da classe operária aprendem as atitudes próprias ao seu papel de subordinação, enquanto os filhos da classe burguesa aprendem os traços sociais do seu papel de dominação. Portanto, podemos verificar a presença do currículo oculto tanto nas escolas públicas como privadas, pois para cada público há aprendizagens necessárias ao seu papel no futuro da sociedade.

Silva (2003, p. 79) também demonstra os elementos que no ambiente escolar contribuem para essas aprendizagens. Uma dessas fontes são as relações sociais estabelecidas no ambiente escolar, da administração até as relações entre os alunos. Outra fonte é a organização do espaço escolar, como os espaços rigidamente organizados da sala de aula tradicional que ensina o individualismo, a obediência e aceitação às ordens; ou os espaços frouxamente estruturados da sala de aula mais aberta que ensinam a cooperação, o trabalho em grupo e a discussão. Uma terceira fonte, citada pelo autor, é o ensino do tempo, em que se aprende a pontualidade, o controle do tempo, 
a divisão do tempo e a delimitação de cada tarefa. Além dessas fontes, há também os rituais, regras, regulamen-

tos, normas e a divisão e categorização explícitas e implícitas dos mais capazes, dos menos capazes, dos meninos e meninas, do currículo acadêmico e do profissional.

Com essa explicitação do que se aprende por meio do currículo oculto, os autores das teorias críticas querem contribuir para que nós, ao nos depararmos com situações como essas, tenhamos consciência das aprendizagens que estão sendo proporcionadas no ambiente escolar, além daqueles que descrevemos nos currículos formais. Nas palavras de SILVA (2003, p. 80),

A ideia é que uma análise baseada nesse conceito permite nos tornarmos conscientes de alguma coisa que até então estava oculta para nossa consciência. A coisa toda consiste, claro, em desocultar o currículo oculto. Parte de sua eficácia reside precisamente nessa sua natureza oculta. O que está implícito na noção de currículo oculto é a ideia de que se conseguirmos desocultá-lo, ele se tornará menos eficaz, ele deixará de ter os efeitos que tem pela única razão de ser oculto. Suspostamente é essa consciência que vai permitir alguma possibilidade de mudança. Tornar-se consciente do currículo oculto significa, de alguma forma, desarmá-lo.

O autor ainda destaca que o conceito do currículo oculto foi muito importante para o desenvolvimento da análise crítica sobre o currículo, pois ele consiste em descrever os processos sociais que moldam nossa subjetividade, sem que tivéssemos consciência disso. "Ele condensa uma preocupação sociológica permanente com os processos ‘invisíveis', com os processos que estão ocultos na compreensão comum que temos da vida cotidiana” (SILVA, 2003, p. 80) da sala de aula. Nesse sentido, o autor destaca que o conceito ainda continua sendo importante.

\section{Contribuições do conceito de Currículo Oculto na formação de professores}

A partir de 1990, várias teorias foram e estão sendo elaboradas numa perspectiva pós-crítica sobre o currículo. Essas teorias partem de uma análise crítica, até então restrita à questão econômica, discutidas anteriormente, e ampliam essa discussão sobre o que se ensina na escola demonstrando que o currículo, tanto o prescrito como o oculto, constrói a identidade dos alunos, constitui a sua subjetividade, a sua forma de ver, escutar e analisar o mundo a sua volta e a si mesmo. Nas palavras de SILVA (2003, p. 15-16),

No fundo das teorias do currículo está, pois, uma questão de "identidade" ou de "subjetividade". Se quisermos recorrer a etimologia da palavra "currículo", que vem do latim curriculum, "pista de corrida" podemos dizer que no curso dessa "corrida" que é o currículo acabamos por nos tornar o que somos. Nas discussões cotidianas, quando pensamos em currículo pensamos apenas em conhecimento, esquecendo-nos de que o conhecimento que constitui o currículo está inextricavelmente, centralmente, vitalmente, envolvido naquilo que somos, naquilo que nos tornamos: na nossa identidade, na nossa subjetividade. Talvez possamos dizer que, além de uma questão de conhecimento, o currículo é também uma questão de identidade. 
$\mathrm{Na}$ análise trazida por essas teorias, os processos de dominação não estão centrados somente na questão de classe social, mas também em outros aspectos como raça, etnia, gênero, sexualidade, entre outros, que quando fogem do padrão da cultura dominante geram desigualdade àqueles que são diferentes da "normalidade". Essas teorias rejeitam a ideia de consciência coerente e centrada, questionam a ideia de subjetividade dizendo que ela é social, ou seja, "eu sou produto do que penso sobre mim e do que os outros dizem de mim". De acordo com Silva (1996, p. 3) "A primeira imagem que uma criança tem de si mesma, na maioria das vezes lhe é dada através da escola, nas relações com os colegas, professores, enfim, nas relações intergrupais e interpessoais que se produzem no espaço-escola".

As representações que os professores têm de seus alunos fazem parte do currículo oculto, daí a necessidade dos professores e futuros professores refletirem sobre esse conceito. Essas representações corroboram com o sucesso ou fracasso escolar. Silva (1996), demonstra como essas representações dos professores definem os alunos e interferem no trabalho pedagógico:

Vamos verificar que muitos professores, logo de saída, já formam uma opinião dos seus alunos. Ou ele é "bom" ou é "mau". E raramente esta opinião muda ao longo do tempo. Assim, as crianças que são mais valorizadas pela escola tendem a melhor se adaptar e alcançar relativo sucesso, ao passo que aquelas outras, que, aliás, são a maioria, acabam sendo eliminadas brutalmente desta escola, nela nada conseguindo. Ao invés de se escolarizarem, se desescolarizam neste tipo de escola, o que mais cedo ou mais tarde acaba fazendo com que essas crianças sejam excluídas, eliminadas do contexto da escola. Assim é que este estigma do fracasso se interioriza de tal forma na maioria dessas crianças, que elas passam a se comportar de acordo com a expectativa que a instituição tem em relação a elas, ou seja, a de crianças inadequadas, mal resolvidas, de péssimo rendimento, em uma palavra, incapazes. O que vai fazer com que se reforce para essas pessoas o mito de que são culpadas pelo seu próprio fracasso, e na medida em que esses futuros trabalhadores ingressem no exército de mão-de-obra disponível à exploração capitalista, serão cada vez mais acomodados, achando que receberam na escola o que deviam receber mesmo, pois são "inferiores" e "incapazes". A função que vão desempenhar na idade adulta não dependerá mais da sua origem de classe, mais do seu "esforço pessoal” (SILVA, 1996, p.3).

Segundo a autora, esse juízo negativo que muitos professores formam de seus alunos manifesta-se de duas maneiras: objetiva e subjetivamente. Objetivamente isso é observado por meio da avaliação, das notas, conceitos e classificações dos alunos, instrumentos objetivos que fazem parte da estrutura organizacional da escola. Subjetivamente esses juízos estão presentes nos comentários, mímicas de desagrado, irritação, intolerância, desprezo etc. Esse tipo de comportamento dos professores ensina muitas coisas aos alunos. Ensinam que uns são capazes, inteligentes, apropriados para receber conhecimentos na escola, outros aprendem que são mesmo burros, incapazes, que não nasceram para a escola. Essas aprendizagens fazem parte do currículo oculto. 
A autora reafirma a importância do currículo oculto para manter as desigualdades sociais ao afirmar que

Portanto, o que queremos mostrar é que o Currículo Oculto tem como função ideológica, através do critério do "esforço pessoal”, preparar os alunos ou para serem dominados ou para serem dominantes neste tipo de sociedade em que vivemos. Pois numa sociedade competitiva como a nossa, a escola também é competitiva, porque nela só se dão bem os "melhores", e é neste tipo de escola que os filhos da classe privilegiada descobrem, muito cedo, a sua "superioridade" e os demais, a sua "inferioridade". Portanto, o critério do "esforço pessoal" tendo como consequência a autodesvalorização e a autovalorização, tem como objetivo perpetuar a origem de classe dos alunos, eliminando, sobretudo, daquele contexto escolar o "mau” aluno. Sim, porque se formos consultar as estatísticas mais recentes, aqueles alunos que reincidem na mesma série, que se evadem da escola, são principalmente, os rotulados de "maus alunos" e "inadaptados" (SILVA, 1996, p. 3).

O argumento que a autora demonstra é que a escola assim como a sociedade neoliberal, é uma instituição competitiva em que terão sucesso aqueles que se destacarem, pois é por meio do esforço pessoal que as pessoas serão bem sucedidas e não porque nasceram numa ou outra classe social. Esse argumento é importante na percepção da atualidade do conceito de currículo oculto na sociedade neoliberal, já que o ocultamento das diferenças sociais e a individualização do sucesso ou fracasso escolar distorcem as origens e perpetuam as desigualdades na sociedade capitalista.

A autora alerta para a importância de uma clareza dos professores para seu papel de reprodutores ideológicos. “Os professores devem ficar atentos aos valores que eles próprios incorporam, porque eles determinam a seleção dos conteúdos, as estratégias, a metodologia, as habilidades e a avaliação. O próprio questionamento, às vezes, está impregnado de ideologia" (SILVA, 1996, p. 4).

Dessa forma, o currículo oculto ainda precisa ser pensado, discutido e estudado nos cursos de formação de professores, tanto inicial como continuada, a fim desses profissionais da educação perceberem que ensinam muito mais do que conscientemente acreditam. Esses ensinamentos ocultos, implícitos, disfarçados, "sem querer”, precisam tornar-se conscientes, desocultados para serem menos perversos.

Tanto o Currículo Real, Oficial (explicitamente) e o Currículo Oculto (implicitamente) têm poder socializador na escola, pois certas práticas e rituais escolares moldam e fabricam consciências. A escola legitima a divisão social, racial e sexual do trabalho, uma vez que o conhecimento escolar é distribuído de forma desigual, conforme os diferentes grupos e classes sociais. A distribuição dos Currículos Ocultos também é diferenciada, de acordo com a classe social, a raça ou etnia e o sexo da clientela. Assim, inculcam-se diferentes atitudes e características de personalidade, de acordo com os diferentes grupos e classes sociais (SILVA, 1996, p. 5). 
Com isso, a autora revela que a escola não tem cumprido a sua função social de transmitir conhecimentos factuais, habilidades e valores, como, por exemplo, a honestidade, e o orgulho da própria herança racial; saber aprender mais, mesmo depois que a escolarização formal tiver terminado; ser intelectualmente aberto; ver-se a si mesmo como parte de uma comunidade democrática; agir cooperativamente.

Mas é possível reverter essa perversidade do currículo oculto e consciente de que se ensina a todo o momento, o professor poderá enfatizar valores positivos, reforçar positivamente a autoestima, consciente de que está ensinando em cada gesto, cada olhar, cada expressão em sala de aula. O que se coloca em questão é a tomada de consciência da existência de ensinamentos que são proporcionados aos alunos, além dos conteúdos das diferentes disciplinas que são lecionadas. Tendo consciência desses ensinamentos seria possível estar alerta, sensível, numa prática profissional ética, a fim de estabelecer um relacionamento na sala de aula pautado no respeito, no diálogo, com atitudes, gestos e linguagens que busquem eliminar da sala de aula formas de preconceitos, discriminações e violências, tendo consciência de que o professor é um exemplo aos seus alunos.

Zeichner (1993) aponta alguns aspectos importantes para um ensino bem-sucedido com crianças pobres e não brancas. Um primeiro aspecto de um ensino bem-sucedido está relacionado com a expectativa do professor acerca da capacidade de seus alunos. Assim, os professores precisam acreditar que todos os alunos podem ser bem-sucedidos e precisam comunicar esta conviç̧ão aos alunos. Do mesmo modo, o professor precisa se empenhar para conseguir êxito de todos.

Outro ponto importante é a criação de um contexto na sala de aula no qual os alunos se sintam valorizados e capazes de obter êxito nos estudos. É preciso criar laço pessoal entre o professor e os seus alunos. "O professor deixa de os ver como 'os outros' e dedica-se tanto ao seu desenvolvimento social e psicológico como escolar" (ZEICHNER, 1993, p. 85), depositando esperanças nos seus êxitos, cuidando para que sejam criadas autoimagens positivas no sentido de eficiência dos alunos.

Outra forma de mostrar a convicção na capacidade dos alunos de vencerem é dando-lhes trabalhos escolares exigentes em vez de programas curriculares fracos e mecânicos.

Enfim, o professor precisa estar em constante estado de alerta na sua prática pedagógica. A ética deve fazer parte da opção profissional, pois está formando pessoas e esse cuidado deve ser redobrado quando se trabalha na formação de professores. Discurso e prática devem caminhar juntos pautados no respeito, na aceitação e convívio com as diferenças. A reflexão sobre as suas concepções, verdades e certezas deve ser constate ao professor para que não repasse mensagens, por meio do currículo oculto, de dominação e subordinação, além de posições preconceituosas com relação à raça/etnia, classe social, gênero, sexualidade, religião etc., pois como alerta Apple (2012), mesmo os professores mais progressistas, por vezes, acabam incorporando a noção, o conceito de "branquidade", vivenciando a sua posição de classe na vida cotidiana. Ele lembra que o conceito foi formulado na análise da teoria crítica, mas deixa claro como ainda precisamos dele para compreendermos as relações que se estabelecem na escola. Segundo ele, isto requer um conhecimento teórico do mundo, uma análise das contradições entre as relações de poder um olhar atento às ações desenvolvidas no âmbito escolar.

3 O conceito de branquidade foi estudado por McLaren (2000), demonstrando que a raça/etnia branca nunca é questionada e está sempre colocada numa condição de superioridade em relação às outras raça/etnias. 


\section{Considerações Finais}

O currículo escolar é formado por todas as aprendizagens que se realizam no ambiente escolar, portanto, ele não é algo neutro, muito pelo contrário, ele é ideológico e carregado de interesses políticos, econômicos e culturais, como já mostravam as teorias críticas do currículo. Atualmente, as teorias pós-críticas do currículo demonstram que ele é uma construção cultural e, como tal, transmite ideologias e concepções impostas por grupos dominantes que embasam e frutificam desigualdades sociais, culturais, raciais, de gênero, dentre outras. Coerente com esta reflexão observa-se por que é tão importante e necessária a discussão sobre o papel do currículo oculto e seus efeitos no âmbito educacional e para a sociedade como um todo, pois sua presença é inegável, em qualquer instituição escolar, seja pública ou privada, e sua influência afeta a aprendizagem dos alunos e o trabalho dos professores.

Assim, o currículo oculto forma as identidades dos alunos, por meio daquilo que se ensina no ambiente escolar de forma implícita, pois ao frequentar a escola, os alunos criam as suas representações sobre as disciplinas e os rituais desse universo, formando identidades e subjetividades. Para Apple (2012), algumas dessas mensagens podem ser positivas, até progressistas. O fato de o professor trabalhar preocupando-se com a criança que está a sua frente revela que as instituições podem ser formadas em torno de uma "ética do cuidado", ou seja, as mensagens que são ensinadas de forma implícita aos alunos também podem ter um carácter positivo na construção de suas identidades, pois do mesmo jeito que se pode fazer o aluno acreditar que não é capaz, é possível mostrar-lhe que ele é sim capaz, inteligente, esforçado, caprichoso etc., ressaltado as suas capacidades, suas qualidades, suas potencialidades.

A atualidade do conceito de Currículo Oculto está no fato de que apesar do contexto explicitamente capitalista e neoliberal que vivemos hoje, da constatação de que se ensina na escola muito mais do que aquilo que está descrito e registrado nos currículos oficiais, se não se discutir, estudar e desvendar essas aprendizagens ocultas, continuaremos reforçando a ideologia da classe dominante e os valores sociais que são tidos como "normais", deixando todos aqueles que fogem, ou não seguem essa normalidade, numa condição de exclusão e desigualdade social que é reproduzida no ambiente escolar.

\section{Referências}

ARAUJO, Viviane Patricia Colloca. Relatório Final de Pesquisa: Currículo oculto nos dias de hoje: revelado ou ainda velado? UNIP: Vice-Reitoria de Pós-Graduação e Pesquisa. Ribeirão Preto - SP, 2018.

ALTHUSSER, Louis. Ideologia e Aparelhos Ideológicos do Estado. $3^{\text {a }}$ ed. Rio de Janeiro: Graal, 1987.

APPLE, Michael. Entrevista. In: SILVA, Maria Vieira; MARQUES, Mara Rúbia Alves; GANDIN, Luís Armando. Contradições e Ambiguidades do Currículo e das Políticas Educacionais Contemporâneas - Entrevista com Michael Apple. Currículo sem Fronteira. v.12, n.1, pp. 175-184, Jan/Abr 2012. Disponível em: <http://www.curriculosemfronteiras.org/vol12iss1articles/silva-marques-gandin.pdf $\geq$ Acesso em: 07 jun. 2018.

BAUDELOT, C.; ESTABLET, R. L'école capitaliste en France. Paris: Maspéro, 1971.

BOURDIEU, Pierre; PASSERON, Jean-Claude. A reprodução. Elementos para uma teoria do sistema escolar. Rio: Francisco Alves, 1975. 
BOWLES, Samuel e GINTIS, Herbert. Schooling in Capitalist America. New York, Basic Books, 1976.

MCLAREN, Peter. Multiculturalismo crítico. 3. ed. São Paulo: Cortez: Instituto Paulo Freire, 2000. 239 p.

MOREIRA, Antônio Flávio. (Org.). Currículo: questões atuais. Campinas: Papirus, 1997.

SANTOMÉ, Jurjo Torres. O Curriculum Oculto. Porto: Porto Editora. 1995.

SILVA, Maria José Lopes. Um aspecto da função ideológica da escola: o currículo oculto. Boletim Técnico do SENAC. v. 22, n.2, maio/agosto 1996. Disponível em: <https://www.oei.es/historico/na2003.htm >. Acesso em: 07 jun. 2018.

SILVA, Tomaz Tadeu da. Documentos de identidade: uma introdução às teorias do currículo. 2. ed. Belo Horizonte: Autêntica, 2003.

ZEICHNER, Kenneth M. A formação reflexiva de professores: ideias e práticas. Lisboa: Educa, 1993.131 p. 